\title{
NOVOS RESULTADOS E ELEMENTOS PARA A ANÁLISE E DEBATE SOBRE A LITERACIA DA INFORMAÇÃO EM PORTUGAL
}

\author{
NUEVOS RESULTADOS Y ELEMENTOS PARA EL ANÁLISIS Y EL \\ DEBATE SOBRE LA ALFABETIZACIÓN INFORMACIONAL EN \\ PORTUGAL
}

\section{Armando M. Barreiros Malheiro da Silva - armando.malheiro@gmail.com Doutor em História Contemporânea. Docente do Curso de Licenciatura em Ciência da Informação da Universidade do Porto. \\ Viviana Fernández Marcial - vivianafernandez@udc.es Doutora em Documentação. Docente da Universidade da Coruña.}

\begin{abstract}
Resumo
Este artigo divulga resultados do Projeto de Pesquisa eLit.pt - A Literacia Informacional no Espaço Europeu do Ensino Superior. Ao longo dos dois anos foram divulgados os pressupostos teórico-metológicos e conceituais além dos resultados parciais dos dois inquéritos distribuídos para uma amostra de mais de três mil estudantes. Um dos inquéritos para alunos do último ano do secundário e outro a alunos do segundo ano do ensino universitário e politécnico. Neste artigo, avançamos com mais alguns resultados e divulgamos os modelos dos inquéritos aplicados. Com mais estes elementos esperamos contribuir para a estimulação de um debate urgente e aprofundado acerca do tema "literacia da informação" que não deve, em nosso entendimento, ser confundida com inclusão digital ou com brecha digital.
\end{abstract}

\section{Palavras-chave}

Competência Informacional. Espaço Europeo de Ensino Superior. Modelo eLit.pt.

\section{INTRODUÇÃO}

Apesar do conceito de Literacia Informacional (LI) ter origem na década de 1970, o seu efectivo desenvolvimento está relacionado com a expansão das tecnologias da informação e a evolução da Era da Informação. Na década de 1990, diferentes países 
iniciaram a reorganização dos seus sistemas educativos. Em 1994, os EUA definiram os seus objectivos educacionais - National Education Goals - onde foi demonstrado que a LI é um factor chave na Era da Informação. Neste período, alguns países Europeus como a Finlândia ou o Reino Unido, desenvolveram acções similares.

A LI é uma questão central para os governos e para as instituições profissionais, culturais, organizacionais e educacionais. Organizações como a UNESCO, a OCDE e a União Europeia, expressaram o seu interesse por este assunto. No contexto europeu foram desenvolvidos vários projectos como o DEDICATE (Distance Education Information Course Through Networks), o EDUCATE (End User Courses in information Access through Communication Technology), o VERITY (Virtual and Electronic Resources for Information Skills Training for Young People), entre outros.

É preciso ademais ter em conta que a assimilação do conceito na prática formativa e cultural dos bibliotecários levou à elaboração de standards, desde os anos 80 , a fim de que os utilizadores das Bibliotecas adquirissem boas práticas na busca, no uso e na citação das fontes procuradas e encontradas nesses espaços próprios dentro do contexto escolar em que desenvolviam as suas actividades. Esses standards e o entendimento subjacente de LI na prática biblioteconómica desenharam um conjunto de ideias orientadoras do papel do bibliotecário, ainda hoje vigentes, quer no seio das Universidades, quer nas Escolas através da figura do professor bibliotecário. Essas ideias vão desde as prescrições elementares e simples, como seja a leitura de catálogos e da sinalética classificativa (por ex. CDU), dos livros e dos periódicos em livre acesso ou os passos certos de uma pesquisa em base de dados bibliográficas, até à promoção da avaliação, da escolha e do uso crítico das fontes disponíveis.

A literacia na prática biblioteconómica adquiriu, assim, um perfil muito associado à indução de competências através do binómio ensino-aprendizagem, que a pesquisa em Ciência da Informação $(\mathrm{Cl})$ deve compreender e ver os efeitos desse esforço "de formação para a literacia informacional" nas pessoas, nos grupos e no próprio sistema educativo. O fenômeno da literacia, vai, pois, muito para além dos standards e das boas práticas, e busca criticamente entender e caracterizar, em profundidade, o perfil de LI dos sujeitos estudados.

$\mathrm{Na}$ nossa concepção de $\mathrm{Cl}$, obtida através da simbiose construtiva dos legados teórico-práticos da Arquivística, da Biblioteconomia, da Documentação e da Ciência da Informação, entendida como disciplina/profissão centrada no processamento e 
recuperação electrónicos de conteúdos, o comportamento informacional constitui uma das três áreas do campo de estudo desta ciência de matriz transdisciplinar, e com natural vocação interdisciplinar, em especial no âmbito das Ciências da Informação e Comunicação (CIC). A Cl é uma ciência social que investiga os problemas, temas e casos relacionados com o fenômeno info-comunicacional perceptível e cognoscível através da confirmação, ou não, das propriedades inerentes à gênese do fluxo, organização e comportamento informacional (origem, colecta, organização, armazenamento, recuperação, interpretação, transmissão, transformação e utilização da informação); e

tem como dispositivo metodológico geral o Método Quadripolar e o seu campo de estudo e intervenção compreende três áreas interligadas a ponto de se interpenetrarem: a [Produção] Gestão da Informação, a Organização e Representação da Informação e o Comportamento Informacional (SILVA, 2006, p. 43).

São áreas que agregam problemas e casos específicos e, neste sentido, é conveniente convocar uma relação hierárquica, do geral para o particular ou vice-versa, entre estes e a área correspondente. Em concreto, entendemos que a inteligibilidade da LI se instaura, em pleno, na área do comportamento informacional, sendo, como este, um tópico endógeno à $\mathrm{Cl}$.

A limitação do processo de literacia a espaços formativos torna o conceito, bastante em voga, da long life literacy, trazido pelas Ciências da Educação e pelas políticas públicas apostadas no combate ao desemprego e à requalificação dos activos demográficos, sinônimo de comportamento informacional e, por consequência, redundante em $\mathrm{Cl}$. No âmbito desta disciplina científica tem vantagem recortar, na área do comportamento informacional, a problemática da LI, desde que centrada em pessoas e grupos sujeitos a contextos de educação formal dentro dos quais é exercido um forte estímulo à busca e uso crítico da informação e podem ser ensinadas estratégias e procedimentos facilitadores desse desiderato.

O que pretendemos enfatizar é que o problema em foco neste artigo não deriva do "património de problemáticas" das disciplinas práticas integrantes da $\mathrm{Cl}$ transdisciplinar, que entendemos ser a resposta epistemológica adequada aos desafios actuais e futuros da Era da Informação e só possível em face da existência, cada vez mais nítida, de um novo paradigma (pós-custodial, informacional e científico). Deriva sim da forte permeabilidade interdisciplinar que ela possui quer dentro da interdiscipina CIC, quer na interacção com as Ciências Humanas e Sociais, onde aquela se insere naturalmente, e com as denominadas Ciências Exactas e Naturais (ou duras). Trata-se, pois, de um problema compósito que por via das trocas interdisciplinares intensas invadiu o campo da Inf. Inf., Londrina, v. 15, n. 1, p. 104- 128, jul./jun. 2010 
Cl e assume, hoje, uma acuidade que não pode ser ignorada. Parece-nos, por isso, oportuno esmiúça-lo com algum detalhe e rigor.

\subsection{0 projecto eLit.pt: objectivos e metodologia}

Tendo como marco teórico as referências operatórias antes descritas, foi apresentado, em 2006, um projecto de investigação à Fundação para a Ciência e Tecnologia (FCT), no âmbito de candidaturas a financiamento científico, e aprovado tendo por titulo A literacia informacional no Espaço Europeu do Ensino Superior: estudo da situação das competências da informação em Portugal (eLit.pt), com início em Junho de 2007 e conclusão definitiva en Maio de 2010. Trata-se de um projecto assumido no campo da $\mathrm{Cl}$, mas aberto a uma efectiva interdisciplinaridade, espelhada na composição da própria equipa com sociólogos, psicólogos e educadores, além de cientistas da informação (SILVA et al., 2008) ${ }^{1}$. O âmbito da pesquisa é nacional e foi elaborado um inquérito, cuja aplicação foi precedida por proveitoso teste de focus group. Neste ponto convém sublinhar os objetivos mais específicos do eLit.pt:

- determinar a existência da LI como a definimos atrás;

- verificar se a LI já é perceptível no fim do Ensino Secundário e se durante todo esse nível de ensino houve alguma "formação para a Ll" no sentido de boas práticas de busca, organização, citação e uso da informação;

- determinar eventuais contrastes entre os níveis de LI no Ensino Secundário e a meio do Ensino Superior (Universitário e Politécnico);

- situar a LI através de diferentes contextos escolares (Secundário e Superior Universitário e Politécnico) nas assimetrias geográfica e socioeconómica de Portugal continental;

- partir do contexto escolar e do desenvolvimento da LI aí ocorrido para determinar outros contextos que se sobrepõem ou se ligam complementarmente no processo de consolidação da literacia nos estudantes portugueses;

- avaliar o esforço há muito desenvolvido através dos standards de LI e até que ponto ele se revela insuficiente ou até inútil para a criação de um efectivo e

\footnotetext{
${ }^{1}$ O coordenador científico é Armando Malheiro da Silva (CETAC.Media-FLUP) e a equipe é formada por s: José Manuel Pereira de Azevedo (CETAC.Media-FLUP), Maria Fernanda Martins (CETAC.Media-FLUP), Manuela Azevedo Pinto (CETAC.Media-FLUP), e Viviana Fernandez Marcial consultora de investigação (Universidade da Coruña).
} 
interiorizado perfil de LI no processo educativo formal em plena Era da Informação e sob o impacto crescente e imprevisível das TIC.

A abordagem seguida baseou-se no estabelecimento de segmentos e de estratificação da amostra, tendo sido adoptados como critérios de selecção os seguintes:

a) examinar o mesmo tipo de área geográfica (normalmente cidades), para Ensino Secundário (ESec) e Ensino Superior (ESup);

b) seleccionar regiões que reflectissem as diferentes situações socioeconómicas;

c) representar o norte, centro e sul do país, assim como o litoral e o interior;

d) incluir na amostra estudantes do $12^{\circ}$ ano do ESec e do segundo ano do ESup, a fim de comparar as competências nos dois diferentes momentos: o anterior à entrada na universidade e durante a frequência do ESup;

e) diferenciar, no ESup, o Ensino Universitário e o Ensino Politécnico, face à possibilidade de existirem diferentes níveis de LI.

Com base nestes critérios resultou uma amostra para a qual foram seleccionadas as cidades do Bragança, Vila Real, Porto, Covilhã, Castelo-Branco, Coimbra, Lisboa, Évora e Faro. Outro critério que foi aplicado na seleção da amostra foi a combinação das diversas áreas de conhecimento (Quadro 1) com o fim de verificar se este feito ia a ter incidência no nível de competências informacionais dos inquiridos.

\begin{tabular}{|c|c|}
\hline ÁREAS CIENTÍFICAS (ESCOLAS SECUNDÁRIAS) & $\begin{array}{l}\text { ÁREAS CIENTÍFICAS (ENSINO SUPERIOR) } \\
\text { BOLONHA - } 1^{\circ} \text { CICLO (3 E } 4^{\circ} \text { SEMESTRES) }\end{array}$ \\
\hline $\begin{array}{l}\text { Ciencias e Tecnologias } \\
\text { Ciencias Socioeconómicas } \\
\text { Ciencias Sociais e Humanas } \\
\text { Artes Visuais }\end{array}$ & $\begin{array}{l}\text { Arquitectura } \\
\text { Arquitectura paisagista } \\
\text { Bioquímica } \\
\text { Contabilidade e Administração } \\
\text { Contabilidade e Gestão Financeira } \\
\text { Enfermagem } \\
\text { Engenharia Civil/P ; Engenharia Civil/U } \\
\text { Gestão de Empresas } \\
\text { Gestão/P ; Gestão/U } \\
\text { Línguas } \\
\text { Línguas e Comunicação } \\
\text { Línguas, Literaturas e Culturas } \\
\text { Psicologia }\end{array}$ \\
\hline
\end{tabular}

Quadro 1 - Relação de áreas científicas da amostra

Os inquéritos foram aplicados a todos os estudantes, em todos os segmentos, de forma a obter pelo menos um número mínimo de 50 inquiridos. A composição final da amostra foi de 10 Escolas Secundárias onde participaram 855 estudantes e de 13 
Insituições do Ensino Superior (universitário e politécnico) com um total de 2271 estudantes.

Com a análise dos resultados da fase qualitativa, desenhou-se um primeiro questionário com uma aplicação piloto a 28 alunos do $12^{\circ}$ ano da Escola Secundária Rodrigues de Freitas e a 19 alunos do $2^{\circ}$ ano de um curso da Faculdade de Letras da Universidade do Porto. As respostas obtidas foram processadas utilizando o software SPSS 15.0. Com base nos resultados obtidos, elaborou-se a versão final do inquérito (Apêndice 1) o qual passou a integrar 54 questões, estruturadas em quatro grupos principais:

- Grupo Básico: inclui o contexto escolar e o familiar, entendido como o espaço onde os estudantes desenvolvem a sua estrutura de comportamento informacional configurando uma forma de lidar com a LI. Entendendo-se por contexto um espaço composto por elementos materiais, tecnológicos e simbólicos (a dimensão institucional de uma entidade, papéis e status dos actores), o presente contexto escolar inclui as instalações da escola/universidade (considerando aqui o edifício em si, a estrutura tecnológica e a instituição/escola) mais os papéis e o estatuto social dos respectivos actores (professores, estudantes, etc.).

- Grupo Funcional: inclui o papel de mediação de instituições como a biblioteca e a escola.

- Grupo Transversal: inclui todas as questões relacionadas com a forma como os estudantes combinam e usam informação diversa. Por exemplo: acesso à informação, avaliação da informação e respectivo uso.

- Grupo Introspectivo: mecanismo interno (motivação) ligado às necessidades de informação.

Seguiu-se a análise dos resultados e a validação do modelo teórico elaborado (Apêndice 2). Neste modelo, partimos dos seguintes preceitos:

- As competências informacionais são co-determinadas, em primeiro lugar, pelas condições do meio e pela acção humana, focada no contexto e na situação.

- O meio determina o contexto e o contexto é mais urgente e uma situação mais pessoal.

- Tudo isto definirá as necessidades de informação. 
- As necessidades de informação determinarão o modo como os estudantes acederão à informação

- Quando os estudantes acedem á informação, um processo de avaliação e seleção é automaticamente activado e este processo é influenciado pela situação, contexto e meio.

- O resultado deste processo é a satisfação ou não-satisfação do estudante.

O Projecto eLit.pt consiste em não ser apenas mais um diagnóstico baseado num minucioso inquérito por questionário que se estendeu a uma amostra ampla de estudantes do último ano do Ensino Secundário e do meio de várias Licenciaturas (desde a àrea de Humanas às Tecnológicas, cobrindo um espectro variado e significativo) do Ensino Superior Público (Universitário e Politécnico), mas, sobretudo, uma pesquisa em Ciência da Informação que foca a problemática da LI como um aspecto integrante e estrutural da área do comportamento informacional. Não se trata, pois, de uma pesquisa híbrida e sem ponto de partida claro - ela parte do campo e com o arsenal teóricometodológico e conceptual da $\mathrm{Cl}$, mas fazendo, naturalmente, interligações com a Educação, a Psico-Pedagogia e a Sociologia.

\section{RESULTADOS}

A análise dos dados gerais sobre a origem social dos inquiridos permite apontar algumas tendências. No que concerne aos estudantes do ESec estes parecem refletir um perfil característico de populações urbanas possuindo $45,6 \%$ das mães um curso Superior, seguindo-se $23,3 \%$ com o Secundário, enquanto que nos pais $35,5 \%$ têm um curso Superior, seguindo-se $25,2 \%$ com o Secundário. Somente $15,2 \%$ dos alunos beneficiam de apoio social escolar. No Ensino Superior existe uma clara diferenciação na origem social dos estudantes do Ensino Universitário e dos do Ensino Politécnico, revelando este último um maior recurso ao apoio social (43\% por oposição a $2,4 \%$ no Ensino Universitário), bem como um menor nível de escolaridade da mãe (no Politécnico $26,6 \%$ com $1^{\circ}$ Ciclo, face a 27,9\% com curso Superior nos do Ensino Universitário) e do pai (no Politécnico $25,8 \%$ com $1^{\circ}$ Ciclo, face a $24,4 \%$ com curso Superior nos do Ensino Universitário). Verifica-se uma provável frequência em escolas com menos recursos já que se apresentam como os que no $1^{\circ}$ Ciclo menos frequentaram a Biblioteca Escolar. $O$ inquérito mostra-nos, ainda, que a maior parte dos inquiridos que frequenta o ESup já possui maior volume de capital escolar do que os seus pais. 
Atentando nos dados gerais obtidos sobre a presença de computadores e das condições de acesso à Internet na vida destes estudantes, verificamos que cerca de 99\% dos inquiridos declara ter computador em casa (destes 60,4 \% do ESec e 62,8\% do ESup têm de 2 a 3 computadores), sendo o número de computadores por agregado familiar maior no Ensino Universitário que no Ensino Politécnico $(33,4 \%$ com mais de 2 computadores no Universitário, face a $25,2 \%$ no Politécnico), o que leva à possibilidade de um uso mais intensivo por parte do estudante universitário (Gráfico 1).

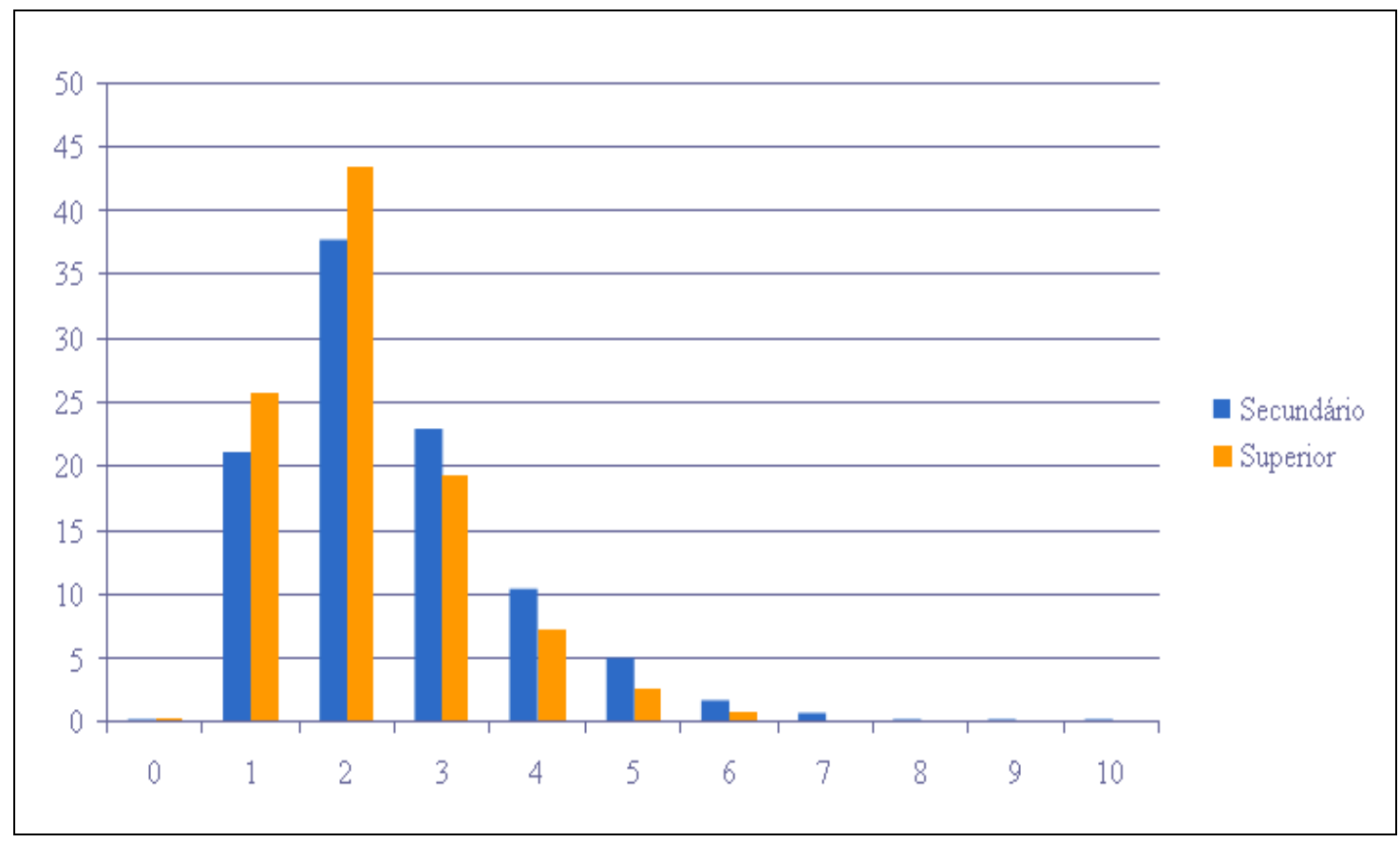

Gráfico 1 - Posse e uso de computador em casa (\%)

O acesso à Internet em casa está também bastante difundido (cerca de $81 \%$ dos inquiridos), sendo que a sua distribuição é mais uma vez favorável aos alunos das Universidades (só 7,2\% não tem ligação, enquanto que no Politécnico atinge os 11,9\%) (Gráfico 2). A frequência de acesso é igualmente diferenciada, sendo os universitários aqueles que acedem com maior frequência. Quando comparado globalmente o ESup com o ESec é o primeiro que revela uma maior frequência de acesso (75,5\% para 68,5\%) evidenciando já comportamentos distintos, nomeadamente no que respeita ao local de onde acedem à Internet (Gráfico 3). Se, em ambos os casos, a 1a opção é o acesso a partir de casa (acima de 90\%), quando se trata do contexto educacional, 57,4\% dos estudantes do ESup afirma fazê-lo na Faculdade e só 19,6\% do ESec o faz na respectiva Escola, apesar de reconhecerem a existência de recursos. É de salientar que 94,7\% dos estudantes do ESec possuem formação em TIC, enquanto que só $53 \%$ dos estudantes do ESup tiveram essa possibilidade. De facto, entra aqui outra variável, indissociável das reformas operadas no sistema educativo e na progressiva inclusão de novas 
disciplinas/conteúdos, que afecta os dois grupos (ESec e ESup - em 2001-2002, achavam-se, respectivamente, no $5^{\circ}$ ano e no $7^{\circ}$ ano de escolaridade).

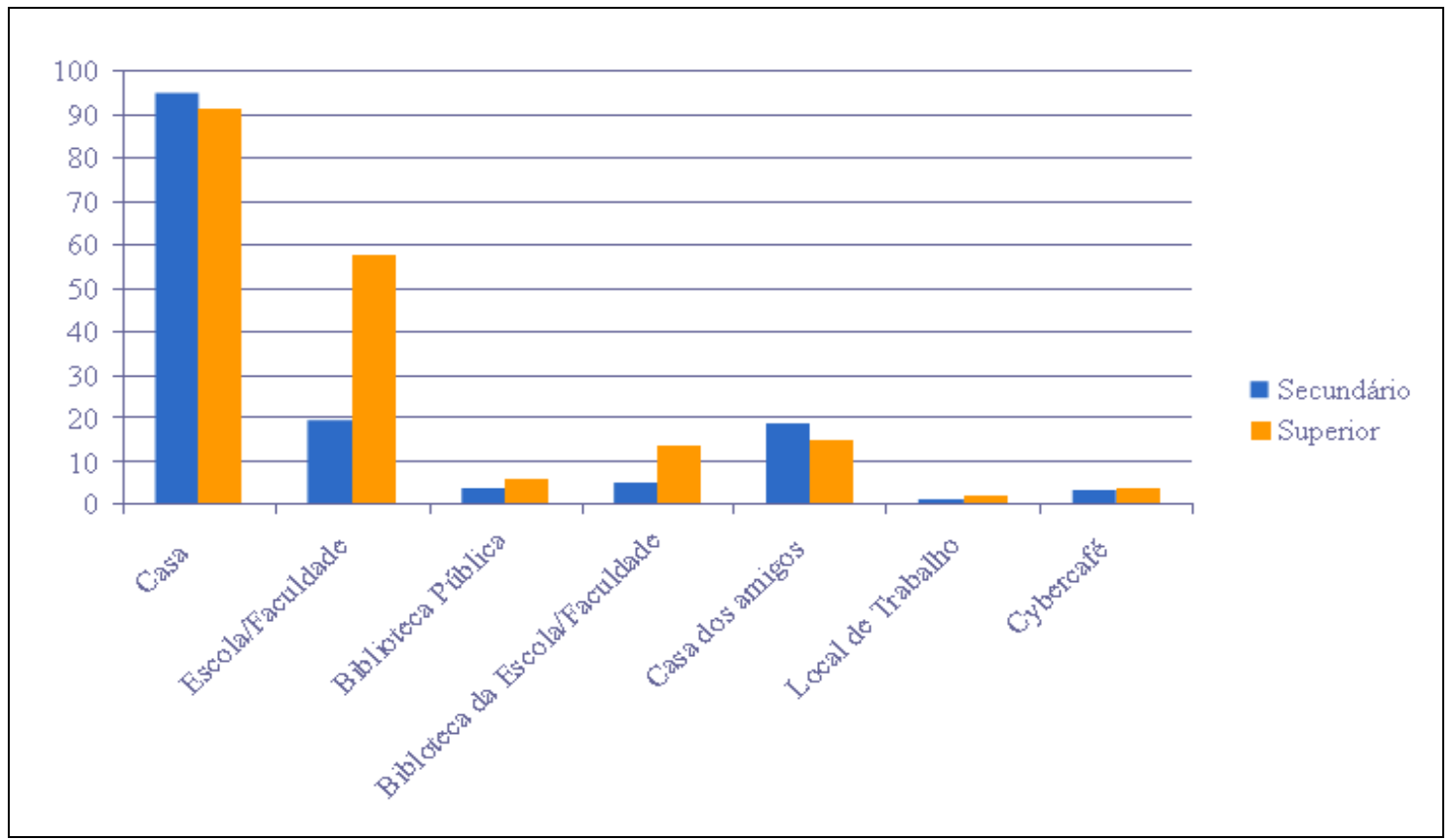

Gráfico 2 - Local onde os inquiridos acedem à Internet (\%)

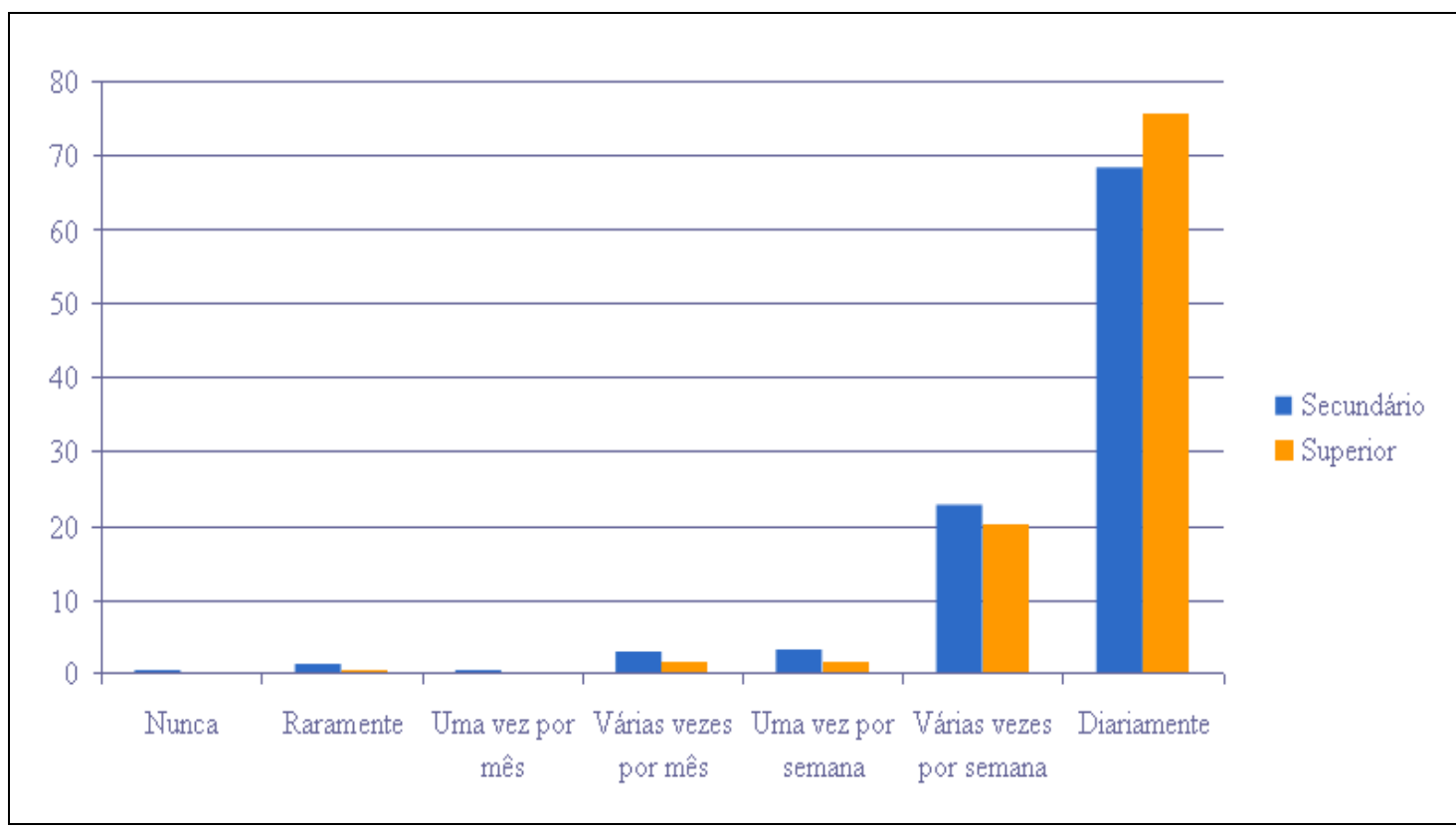

Gráfico 3 - Frequência com que acedem à Internet (\%)

Verifica-se, ainda, que a desigual distribuição de recursos entre Ensino Universitário e Politécnico assenta, também, numa desigual distribuição geográfica. Assim, as maiores taxas de acesso encontram-se nas maiores cidades (Gráfico 4). 


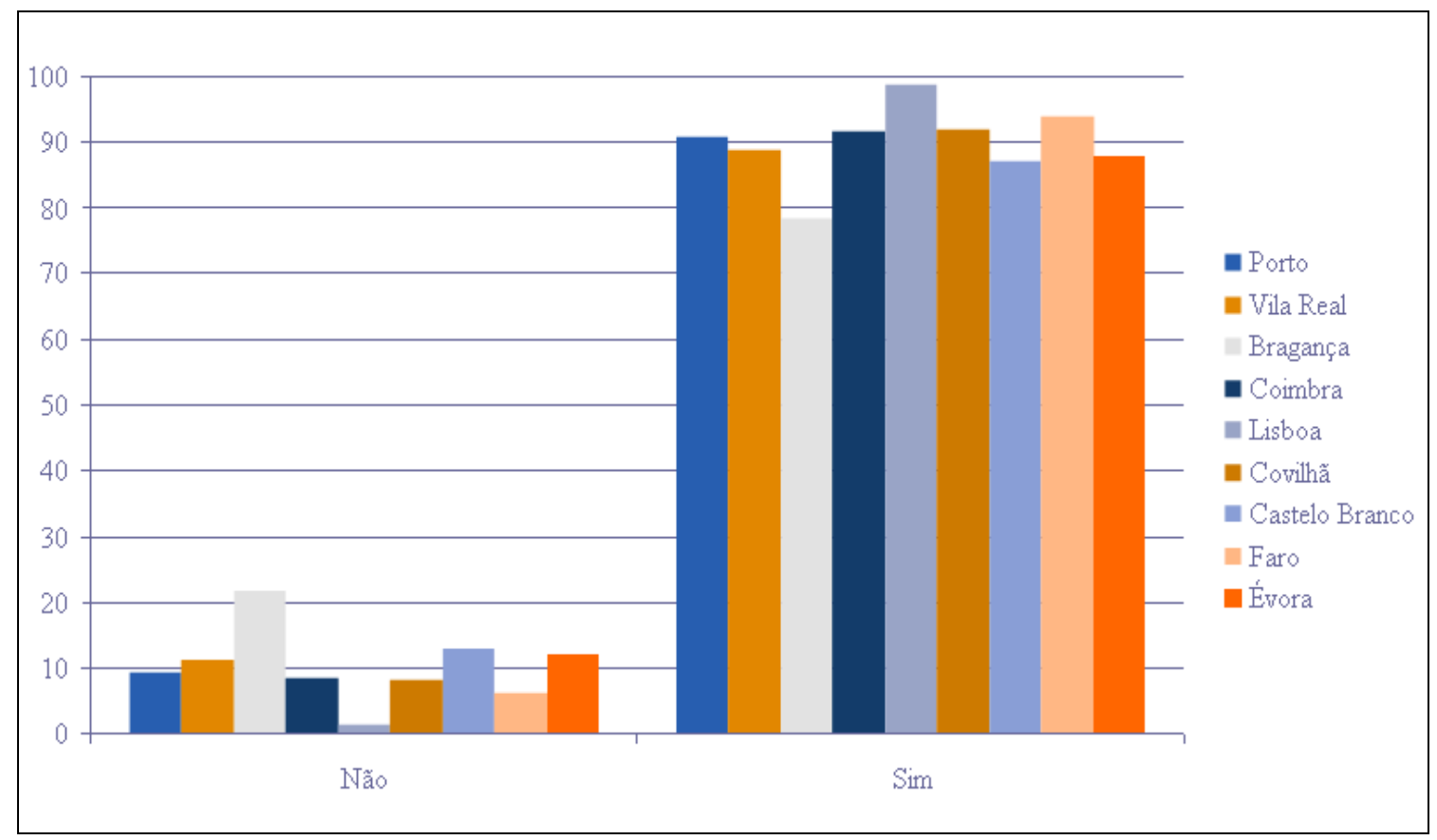

Gráfico 4 - Ligação à Internet em casa / cidade da Inst. Ensino - Inquiridos do ESup (\%)

De uma forma geral, e não obstante o bom apertrechamento tecnológico, a diferenciação social e as assimetrias verificadas no acesso e no uso das tecnologias de informação e comunicação, bem como dos recursos de informação, parecem esboçar a existência de uma "brecha informacional" (informational divide) a par da já identificada "brecha digital" (digital divide). Convocando o conceito de LI estes dados parecem sugerir que no contexto escolar é preciso fazer algo de substancial na dimensão das competências cognitivas para que tal "brecha" diminua ou desapareça. Contudo, e por si só, o contexto socioeconómico e familiar não parece ter especial relevância no comportamento informacional, apontando estes resultados para a influência de variáveis oriundas do próprio contexto escolar.

Na verdade, se para os alunos do ESec a escola dá formação e possibilita o acesso a serviços e recursos, não constitui para estes alunos o local preferido para os usar, nem mesmo quando o objectivo são trabalhos escolares. Sendo elevado o número de disciplinas que solicitam trabalhos, é novamente em casa que os alunos do ESec os realizam (96,6\%), surgindo aqui uma outra diferenciação face aos estudantes do ESup que, apesar de também tenderem a preferir a sua casa $(81,1 \%)$, manifestam um uso mais intensivo quer do espaço/recursos da Faculdade (64,6\%), quer da Biblioteca aí localizada $(42,1 \%)$, a funcionar de um modo tendencialmente especializado. Os trabalhos, que os alunos do ESup têm de elaborar para as diversas disciplinas dos cursos que freqüentam, encontram-se na origem de necessidades e problemas de acesso e uso de informação mais complexos, que têm de ser solucionados, sendo visível a maior importância atribuída 
aos recursos oferecidos pela Faculdade, normalmente mais específicos, em maior abundância e de maior qualidade.

Apesar de não recorrerem à biblioteca escolar para elaborarem os seus trabalhos escolares, nem por isso os nossos inquiridos deixam de a utilizar. A percentagem de alunos que declarou nunca ter visitado este equipamento fica-se pelos $22,4 \%$. Note-se que, de forma não surpreendente, os inquiridos que disseram ter frequentado a biblioteca no $3^{\circ}$ ciclo de ensino - 69,7\% - são, claramente, em maior número do que aqueles que afirmam tê-lo feito no 2 ํㅣㅇㅣ $(47,7 \%)$ e, principalmente, no primeiro ciclo $(18,7 \%)$.

Se analisarmos a utilização que os inquiridos do ESup faziam da biblioteca da sua escola quando eram alunos do ensino básico, verificamos que apenas uma minoria de $15,9 \%$ de inquiridos nunca usufruiu desse equipamento. 60,9\% dos estudantes do ESup declararam ter frequentado a biblioteca escolar quando se encontravam no $3^{\circ}$ ciclo do ensino básico. É de notar, que os actuais alunos do secundário frequentavam com maior frequência a biblioteca escolar quando ainda se encontravam no ensino básico do que os jovens que estudam agora no ensino superior.

Revisando o aspecto referido - a utilização da biblioteca da Faculdade -, constatamos que, de um modo geral, os estudantes do ESup recorrem com frequência apreciável a este serviço. É certo que apenas $4,7 \%$ dos inquiridos o fazem diariamente, mas a percentagem daqueles que utilizam a biblioteca várias vezes por semana ascende a $28,5 \%$. Apenas uma minoria residual de estudantes - 1,9\% - declarou nunca ter usado a biblioteca da sua instituição de ensino ainda que a percentagem de discentes que revelou fazê-lo de modo ocasional atinja um valor apreciável, correspondente a 23,9\%. Ainda assim, cerca de três quartos (74,2\%) dos indivíduos que integram a nossa amostra se deslocam à biblioteca da Faculdade pelo menos uma vez por mês.

Uma comparação entre as duas versões do inquérito sugere-nos que a utilização da biblioteca da respectiva instituição de ensino aumenta muito significativamente com a transição do ESec para o ESup, provavelmente como resposta a necessidades e problemas informacionais crescentes.

Tão importante como perceber o que é que os alunos fazem na biblioteca escolar ou da Faculdade, é saber quais os recursos da mesma que utilizam. Tentamos, assim, medir a frequência com que os inquiridos utilizam as diversas ferramentas que aquele espaço Ihes disponibiliza. À excepção do acesso livre, as percentagens de indivíduos que nunca utilizam os diversos recursos é sempre superior a $50 \%$. O acesso livre é, claramente, 
contrário à tendência geral; ainda assim, apenas 11,2\% dos estudantes o utilizam frequentemente, enquanto que $5,1 \%$ declaram utilizá-lo muito frequentemente. Daqui podem ser extraídas duas conclusões alternativas: ou existe uma subutilização, por parte dos alunos, dos instrumentos que se encontram à sua disposição nas bibliotecas escolares; ou estas fornecem um número limitado de recursos.

Com relação ao estudantes de ESup vemos que de acordo com as respostas obtidas, elaborar trabalhos para o curso, pesquisar informação para estudo, e estudar são as actividades mais comuns, sendo citadas, respectivamente, por $66,1 \%, 62,1 \%$ e $69,2 \%$ dos inquiridos. 46,6\% dos estudantes declarou que utiliza a biblioteca da sua Faculdade para requisitar material. Se uma percentagem elevada de estudantes do secundário afirmou usar a biblioteca da sua instituição de ensino para aceder à Internet, apenas $29,3 \%$ dos alunos do superior referem essa finalidade. Parece-nos que entre os estudantes dos dois níveis de ensino poderão existir não só diferentes taxas de utilização daquele equipamento, mas também diferentes modos de utilização do mesmo.

Observando os quadros que de seguida se apresentam, facilmente se conclui que os estudantes do ESup, de uma maneira geral, utilizam uma maior diversidade de recursos da biblioteca da sua instituição de ensino do que os alunos do secundário (Tabela 2). Resta saber se isto se deve a uma maior necessidade de procura de informação, à disponibilização, por parte da biblioteca, de maior número de recursos, ou à combinação destes dois factores. Ainda assim, podemos considerar que a utilização desses recursos é baixa. Destaca-se o acesso livre, com níveis de utilização claramente superiores aos de outros recursos.

\begin{tabular}{|l|c|c|c|c|c|}
\hline \multicolumn{1}{|c|}{ Recurso BF: } & $\begin{array}{c}\text { Catálogo } \\
\text { de fichas }\end{array}$ & $\begin{array}{c}\text { Acceso } \\
\text { livre }\end{array}$ & $\begin{array}{c}\text { Biblioteca } \\
\text { digital }\end{array}$ & $\begin{array}{c}\text { Catálogo } \\
\text { electrónico }\end{array}$ & $\begin{array}{c}\text { Bases } \\
\text { de } \\
\text { dados }\end{array}$ \\
\hline Nunca & 52,0 & 17,9 & 37,5 & 38,9 & 33,3 \\
\hline Raramente & 26,9 & 18,9 & 26,4 & 23,7 & 22,8 \\
\hline Às vezes & 16,6 & 31,0 & 22,3 & 20,0 & 23,6 \\
\hline Frequentemente & 3,6 & 23,5 & 10,2 & 12,3 & 13,6 \\
\hline $\begin{array}{l}\text { Muito } \\
\text { frequentemente }\end{array}$ & 0,8 & 8,7 & 3,5 & 5,1 & 6,6 \\
\hline
\end{tabular}

Quadro 2 - Frequência de utilização dos recursos da biblioteca da faculdade (\%)

No momento de valorar o papel de intermediação da biblioteca, da escola, da família, perguntamos aos alunos que reconheceram sentir dificuldades na utilização dos recursos da biblioteca a quem recorrem para dar resposta às suas dúvidas. Um número muito significativo de inquiridos referiu solicitar ajuda habitualmente ao bibliotecário: 48.3\% de estudantes do secundário e $69,2 \%$ do superior. Refira-se ainda que cerca de Inf. Inf., Londrina, v. 15, n. 1, p. 104- 128, jul./jun. 2010 
metade $(51,3 \%)$ dos discentes mencionou pedir auxílio aos professores. Este é um dado curioso, uma vez que nos mostra que a tendência para recorrer à ajuda de docentes para lidar com dificuldades sentidas na utilização da biblioteca é claramente maior neste patamar de ensino do que no secundário.

Verificamos, assim, que embora os inquiridos procurem resolver as suas necessidades de informação recorrendo à biblioteca escolar ou da sua faculdade, fazemno de modo irregular e principalmente para satisfazer parte dessas necessidades induzidas pela escola.

Resta-nos analisar um outro espaço que se assume como local privilegiado para que os sujeitos possam resolver os seus problemas relacionados com o acesso à informação e a manipulação da mesma: a biblioteca pública.

Com surpresa constatamos que apenas $72,5 \%$ dos inquiridos do ESec afirmam existir uma biblioteca pública na sua área de residência. Surpreendemo-nos porque sabemos que todos os concelhos de residência dos inquiridos (tanto em tempo de aulas como fora dele) estão equipados com bibliotecas municipais. Daqui podem resultar duas interpretações. Os inquiridos poderão não ter interpretado "área de residência" enquanto concelho e terão adoptado unidades espaciais de referência mais circunscritas (freguesia, por exemplo) onde realmente não existem bibliotecas públicas. Por outro lado, estes resultados também poderão indicar um elevado grau de desconhecimento, por parte destes jovens estudantes, dos equipamentos existentes no local onde habitam. Este segundo caminho explicativo aponta para um distanciamento entre os jovens e a rede de bibliotecas públicas.

A hipótese deste feito parece reforçada pelas respostas à questão "com que frequência vais à biblioteca pública". Os resultados mostran que $45,1 \%$ dos inquiridos nunca o fazem, enquanto que $41,1 \%$ apenas a visitam excepcionalmente. A percentagem de utilizadores regulares - mesmo que consideremos a frequência mensal como nível mínimo de regularidade - é muito baixa face aos $86,2 \%$ de inquiridos que ou não a utilizam, ou raramente o fazem.

Uma muito elevada percentagem de inquiridos - 82,2\% - aponta a existência de uma biblioteca pública na sua área de residência. Apesar disto, muito poucos estudantes do ESup utilizam as suas instalações com regularidade. A percentagem de discentes que raramente visita este espaço é de $49,4 \%$; ao mesmo tempo, o peso daqueles que nunca o faz também é muito significativo: $33,2 \%$. Ou seja: $82,6 \%$ dos nossos inquiridos nunca se 
desloca à biblioteca pública ou apenas o faz excepcionalmente. Quanto à existência de computadores com ligação à Internet nestes espaços, ela é apontada por 93,1\% dos inquiridos. Ainda assim, os estudantes do superior demonstram estar mais familiarizados com as bibliotecas públicas do que os alunos do secundário.

Ante esta situação, a pergunta é que meios utilizam os estudantes para o aceso á informação. No lote de recursos utilizados pelos alunos analisaram-se os resultados relativos aos que têm uma ligação mais específica a conteúdos escolares (YouTube, Wikipédia e $b$-on) e foi possível concluir que os estudantes em média utilizam mais o YouTube $(M=3,99, D P=0,97)$ e a Wikipédia $(M=3,67, D P=0,99)$, sendo a $b$-on o recurso menos utilizado $(M=1,38, D P=1,09)(F(10,4618)=88,01, p=0,000)$.

Mais uma vez os resultados indicam a necessidade de formação para que se rentabilize a utilização destes recursos em termos educativos.

Relativamente ao tipo de trabalho preferido constatou-se que os alunos preferem realizar trabalho de grupo a trabalho individual numa percentagem de $67,1 \%$ no caso do Politécnico, de 55,9\% no Universitário e de 68,6\% no ESec $\left(X^{2}(2)=46,36, p=0,000\right)$. Verifica-se que nos universitários esta preferência é menos acentuada. Estes resultados podem indiciar que no universitário o gosto pela autonomia se torna mais evidente.

Há uma diferença estatisticamente significativa relativamente à percentagem de alunos que usa os diferentes suportes de entrega de trabalhos $\left(X^{2}(4)=51,05, p=0,000\right.$ ). No Politécnico $69,5 \%$ e no Secundário $65,2 \%$ usam ambos os suportes (papel e electrónico), enquanto no Universitário apenas 56,3\% usam ambos. É no Universitário que o papel é mais usado (40,2\%; Secundário - 30,1\% e Politécnico - 27,4\%) e no Secundário que o suporte electrónico é mais usado (4,7\%; Politécnico - 3\% e Universitário - 3,5\%).

Os resultados podem indicar que os hábitos escolares estão a mudar e reflectem-se mais rapidamente ao nível do secundário. Por outro lado, a Universidade continua a ser uma instituição mais conservadora e na fase de transição em que estamos ocorrem ainda resistências.

Há uma diferença estatisticamente significativa relativamente à percentagem de alunos que usa os diferentes suportes de apresentação de trabalhos. No ensino politécnico o powerpoint é mais usado $(92,4 \%)$, no universitário é usado por $88,4 \%$ e, no secundário, por $82,9 \%\left(X^{2}(2)=32,09, p=0,000\right)$. É no ESec que a apresentação oral sem suporte electrónico é mais elevada (63,8\%; Politécnico - 43,2\% e Universitário - 47,8\%) 
$\left(X^{2}(2)=74,39, p=0,000\right)$. No ESec o flash é mais usado $(2,6 \%$; Politécnico $-1,3 \%$ e Universitário $-0,5 \%)\left(X^{2}(2)=15,11, p=0,001\right)$.

Estes resultados indicam que no ESec a exigência de apresentação dos trabalhos com ajuda de suporte electrónico é menor o que poderá acontecer por falta de equipamento. Também a utilização do flash pelos alunos do secundário pode revelar a adesão cada vez mais rápida deste nível de ensino às TIC.

Analisaram-se as diferenças entre as fontes para a realização dos trabalhos nos diversos níveis de ensino, tendo-se encontrado diferenças significativas. Os resultados mais salientes indicam que os estudantes em média utilizam mais os motores de busca para a realização dos trabalhos e, por último, os materiais existentes na biblioteca pública. Assim, as TIC ultrapassam os meios clássicos de realização dos trabalhos o que aponta para a necessidade de formação de modo a melhorar a qualidade desta utilização.

A percentagem de estudantes que lêem e tiram apontamentos é idêntica, não apresentando diferenças estatisticamente significativas entre os níveis de ensino. Há mais alunos do secundário a fazer cópia textual $(16,5 \%)$ do que no politécnico $(11,8 \%)$ ou no universitário (10\%).

Por outro lado, há uma percentagem menor de alunos do secundário a comparar leituras (30,5\%; Politécnico - 40,6\% e Universitário - 43,3\%) e a avaliar a autoria (Secundário 6,4\%, Politécnico $13 \%$ e Universitário $10,4 \%)\left(X^{2}(2)=20,93, p=0,000\right)$. Isto aponta que há uma evolução do nível de literacia do secundário para o superior, dada a diminuição nos valores da cópia literal e a maior preocupação com a autoria.

Há uma diferença estatisticamente significativa em relação à percentagem de alunos que recorre a diferentes pessoas para pedir ajuda para a realização dos trabalhos em cada nível de ensino. Os alunos do secundário não pedem ajuda (23,1\%; no Politécnico $4,6 \%$ e no Universitário - $7 \%)\left(X^{2}(2)=188,08, p=0,000\right)$ ou pedem a familiares $(33,7 \%$; no Politécnico $11,9 \%$ e no Universitário $14,3 \%)\left(X^{2}(2)=168,56, p=0,000\right)$, os do politécnico pedem ajuda ao grupo (59,9\%; no Secundário $43,7 \%$ e no Universitário $52,9 \%)\left(X^{2}(2)=\right.$ $45,57, p=0,000)$ e os universitários pedem aos colegas (67,3\%; no Secundário $43,7 \%$ e no Politécnico $64,3 \%)\left(x^{2}(2)=130,44, p=0,000\right)$ e aos professores $(55,2 \%$; no Secundário $31,9 \%$ e no Politécnico $55,7 \%)\left(X^{2}(2)=135,48, p=0,000\right)$.

Os resultados indiciam que o recurso aos familiares é mais fácil durante 0 secundário e que o nível de conhecimentos de cada aluno pode ser mais diferenciado no superior, resultando no maior recurso aos colegas/grupo. 


\section{CONSIDERAÇÕES FINAIS}

A primeira consideração é que parece confirmar-se o facto de que o modelo teórico eLit constitui um referente conceptual válido para explicar o fenómeno da LI. Globalmente, podemos verificar que o meio ambiente, os contextos e as situações definem o comportamento informacional, nunca esquecendo que a informação é estruturada pela acção.

Neste sentido, cabe destacar que, na medida em que os estudantes têm maior obrigação ou compromisso no desenvolvimento das suas tarefas académicas, maior é a importância que atribuem ao uso da informação, o que se repercute de forma positiva no referido comportamento informacional. Esta tendência confirma uma das nossas principais hipóteses de trabalho, isto é, a incidência das necessidades da informação na motivação, evidenciada na qualidade do acesso, do uso, da avaliação e da comunicação da informação.

Comprovamos, também, o valor do enfoque que decidimos atribuir à comparação dos resultados obtidos no ESec e os obtidos no ESup. É-nos, pois, possível demonstrar que durante todo o processo ocorrem diferenças em alguns indicadores, manifestando os estudantes do superior uma maior qualidade no seu nível de LI. Algumas destas diferenças reportam-se à utilização das bibliotecas e de outros meios formais de acesso à informação. Através dos resultados obtidos podemos comprovar que, de maneira geral, os estudantes manifestam uma acentuada e reiterada utilização dos motores de busca, em detrimento de recursos mais qualificados, nomeadamente o biblioteconómico. Surpreende que, no âmbito educativo em que trabalhamos, um estudante confira uma maior credibilidade à informação que encontra no Google, do que à obtida num recurso como a b-on.

Daqui podemos ressaltar outra questão chave, essencial para compreender o ponto em que nos situamos. Referimo-nos a um uso das bibliotecas, sejam elas públicas, escolares ou universitárias, muito inferior ao nível esperado, e, por isso, os esforços destas instituições para melhorar ou incidir na melhoria dos níveis de LI, intervindo activamente no processo de ensino/aprendizagem, vêem-se consideravelmente reduzidos. Esta afirmação correlaciona-se com outra incontornável: há um problema mais profundo que tem as suas raízes nas diversas facetas dos indivíduos, do sistema educativo e da sociedade. 
Os resultados permitem antever como a orientação para efectuar pesquisas e usar a informação é uma tarefa que deve constituir parte integrante do processo de ensino/aprendizagem, assumindo o professor um papel importante, mas que não pode ignorar a influência dos amigos e da família neste âmbito. Daí a necessidade de trabalhar no sentido de uma articulação entre a tríade educacional formal (professor, aluno e biblioteca escolar) e o nível informal, composto por uma mistura de grupos/parceiros, sem esquecer o papel das TIC e a sua influência na motivação e satisfação dos estudantes, considerando que estamos perante uma geração "nativa digital".

A análise conduz, naturalmente, à proposta de medidas de intervenção. Contudo, não consideramos que o problema da $\mathrm{LI}$ se possa resolver com um conjunto de receitas. Constatamos que o Espaço Europeu de Ensino Superior traz novas exigências aos estudantes, tornando-se evidente que estes não possuem o nível desejado para responder com sucesso a estas novas demandas. É evidente, também, que o papel dos diferentes agentes é muito importante na hora de levar a cabo as medidas e as acções necessárias, mas o que é verdadeiramente crucial é o estabelecimento de uma política educativa que trabalhe na busca da referida articulação entre os agentes/actores centrais e que evidencie um verdadeiro interesse e compromisso para com o problema da $\mathrm{LI}$ em Portugal.

\section{REFERÊNCIAS}

SILVA, A. M. da. A Informação: da compreensão do fenômeno e construção do objecto científico. Porto: Edições Afrontamento; CETAC.MEDIA, 2006.

SILVA, A. M. da et al. Espaço europeu de ensino superior e a literacia informacional: conceitos e objectivos de um projecto de pesquisa. Páginas a\&b, Porto, série 1, n. 21, p. 103-123, 2008.

\section{Title}

New results and elements for the analysis and discussion on information Literacy in Portugal

\section{Abstract}

It discloses the results of a Research Project eLit.pt - Information literacy in the European Higher Education Area, granted by the Fundação para a Ciência e Tecnologia (FCT), that since the last two years has published theoretical, methodological and conceptual aspects as well as the partial qualitative and quantitative results on a survey applied to more than three thousand students composed. In this article, more advanced results are presented as well as the survey procedures 
which were adopted by the investigation. It expects to enhance the debate on information literacy which should not be mistaken as digital inclusion or digital gap.

\section{Keywords}

Information Literacy. European Higher Education Area. eLit.pt model

\section{Título}

Nuevos resultados y elementos para el análisis y el debate sobre la Alfabetización Informacional en Portugal

\section{Resumen}

Este artículo divulga los resultados del proyecto de investigación elit.pt-Alfabetización informacional en el Espacio Europeo de Educación Superior: estudio del nivel de competencias informacionales en Portugal. A lo largo de los dos últimos años de desarrollo hemos divulgado los aspectos teórico-metodológicos y conceptuales así como los resultados parciales de una investigación cualitativa y cuantitativa realizada a una muestra de más de tres mil estudiantes integrado por alumnos de último curso de Bachillerato y estudiantes de segundo año de enseñanza universitaria y politécnica. En este artículo, estando terminado el proyecto, avanzamos algunos resultados y el modelo de cuestionario aplicado. Un aspecto central de la investigación es la de contribuir al debate sobre los diversos aspectos sociales, educacionales, tecnológicos que condicionan el fenómeno de la alfabetización informacional.

\section{Palabras Clave}

Alfabetización informacional. Espacio Europeo de Educación Superior. modelo eLit.pt.

Recebido em: 21.08.2009

Aceito em: 15.09 .2010 


\section{APÊNDICE 1 - MODELO DE INQUÉRITO PARA ENSIO SECONDARIO}

Ensino Secundário

NN..

Inquérito ao $12^{\circ}$ ano

\section{OBJECTIVO:}

- Diagnóstico e definição de perspectivas de como os estudantes universitários enfrentam e se ajustam às novas exigências implicadas pela criação no Espaço Europeu de Ensino Superior de uma instrução mais elevada (EEES).

- Saber como são preparados em competências da informação, quer aquando do acesso ao ensino superior, quer quando terminam a sua formação superior.

As informações prestadas são objecto de tratamento estatístico estando garantida a sua confidencialidade.

\section{OBSERVAÇÕES:}

- Nas questões apresentadas podes seleccionar uma ou mais das opções de resposta, com excepção dos casos em que te é pedido que selecciones apenas uma das opções dadas.

- *Biblioteca Digital: Repositório e serviço especialmente constituído para disponibilizar informação em suporte electrónico.

- Biblioteca Escolar: BE | Biblioteca Pública: BP

\section{CONTEXTO PESSOAL}

1. Sexo:

2. Idade:
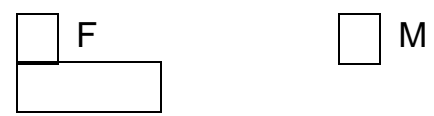

3. Residência durante o período de aulas:

Concelho:

3.1. Residência fora do período de aulas, se diferente:

Concelho:

4. Área de Ensino:

5. És beneficiário de apoio social escolar?

6. Nível de escolaridade da mãe:

$\square$ Sem grau $\square{ }^{10}$ ciclo $\square 22^{\circ}$ ciclo $\square{ }^{30}$ ciclo $\square$ Secundário $\square$ Superior

7. Nível de escolaridade do pai:

$\square$ Sem grau $\square 1^{\circ}$ ciclo $\square 2^{\circ}$ ciclo $\square 3^{\circ}$ ciclo $\square$ Secundário $\square$ Superior

8. Quantos computadores tens em casa?

8.1 São:

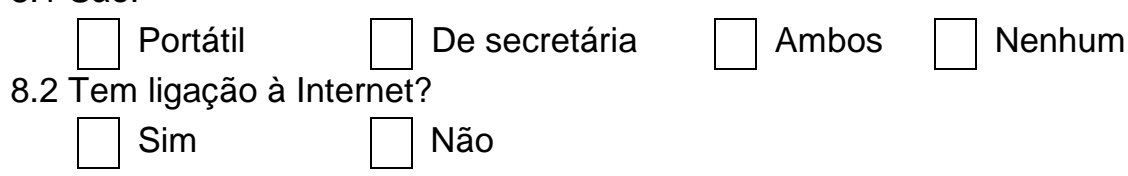

9. Porque continuaste a estudar depois do $9{ }^{\circ}$ ano:
Saber mais
Gostar de estudar
$\rightarrow$ Arra
Ter um curso superior
Arranjar um emprego melhor
Pressão familiar

\section{CONTEXTO ESCOLAR}

10. Frequentas:
Aulas de apoio
Explicações
Nenhuma 
11. Na escola tens acesso a que tipo de computadores:
$\square$ Portátil
De secretária
11.1 Têm acesso à Internet?
11.2 Existe rede wireless na tua escola?

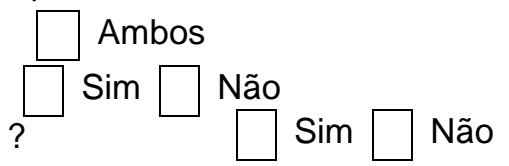

12. Na escola frequentas, ou frequentaste, alguma disciplina relacionada com Tecnologias de Informação e Comunicação (TIC)?

$\square \operatorname{Sim} \square$ Não

13. Os trabalhos académicos que fazes, na maioria são:
$\square$ De grupo
$\square$ Individuais
Ambos

13.1 Preferes:

$\square$ Trabalho de grupo

13.2 Número de disciplinas em que te são pedidos trabalhos:

13.3 O professor diz-te como deves fazer a pesquisa para o trabalho?

onde pesquisar; que termos utilizar; etc.)?

$\square \operatorname{Sim} \square$ Não

13.4 O professor diz-te como deves fazer a estruturação do trabalho (introdução; pontos a desenvolver; etc.)?

$\square \operatorname{Sim} \square$ Não

14. Onde realizas os trabalhos?

$\square$ Casa $\square$ Escola $\square$ Biblioteca da Escola (BE) $\square$ Biblioteca Pública (BP)
Outro:

\section{UTILIZAÇÃO DA BIBLIOTECA ESCOLAR}

15.Frequentaste a Biblioteca Escolar (BE) no:
$\square 1^{\circ}$ ciclo
$\square$ 20 ciclo
$\square 3^{\circ}$ ciclo
$\square$ Nenhum

16. Com que frequência vais à $B E$ ?
$\square$ Nunca
1 vez na semana

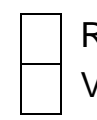
Raramente
$\square 1$ vez no mês Várias vezes na semana

17. Na BE os computadores têm acesso à Internet?

18. Na BE:

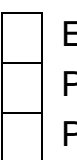
Estudas
Pesquisas e acedes a informação da biblioteca para estudo
Pesquisas e acedes a informação da biblioteca para lazer

- Se sim, utilizas esta informação para estudo?

$\square \operatorname{Sim}$

Fazes trabalhos

Utilizas a Internet

Requisitas material

Outra:

19. Na BE existe formação de utilizadores?

20. Frequência de utilização dos recursos da BE:

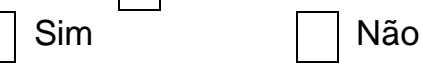

Várias vezes no mês Diariamente

\begin{tabular}{|l|l|l|l|l|l|}
\cline { 2 - 6 } \multicolumn{1}{l|}{} & Nunca & Raramente & Às vezes & Frequentemente & Muito frequentemente \\
\hline Catálogo de fichas & & & & & \\
\hline Acesso livre & & & & & \\
\hline *Biblioteca Digital & & & & & \\
\hline Catálogo electrónico & & & & & \\
\hline $\begin{array}{l}\text { Bases de dados } \\
\text { electrónicas }\end{array}$ & & & & & \\
\hline
\end{tabular}

Inf. Inf., Londrina, v. 15, n. 1, p. 104- 128, jul./jun. 2010 
21. Sentes dificuldade em usar os recursos da BE?

$\square \operatorname{Sim}$ Não

21.1. Se sim, a quem recorres para dar resposta a essas dificuldades?

\begin{tabular}{|l|l|l}
$\square$ & $\begin{array}{l}\text { Professor Bibliotecário } \\
\text { Colegas } \\
\text { Outro: }\end{array}$ & $\begin{array}{l}\text { Pessoal de apoio } \square \text { Professores } \\
\text { Oniliares }\end{array}$ \\
\end{tabular}

22. Que tipo de recursos de informação a BE te disponibiliza?

\begin{tabular}{|l|l} 
Livros \\
Vídeos \\
Informação em formato electrónico
\end{tabular}$\quad \square$ Jornais $\begin{aligned} & \text { Revistas } \\
& \text { Jogos }\end{aligned}$

Outro:

\section{UTILIZAÇÃO DA BIBLIOTECA PÚBLICA}

23. Existe $B P$ na tua área de residência?

24. Com que frequência vais à $B P$ ?
Nunca
1 vez na semana
$\square$ Raramente
Várias vezes na semana
25. Na BP os computadores têm acesso à Internet?
1 vez no mês
semana
$\square \operatorname{Sim}$
$\square$ Várias vezes no mês
Diariamente
Não

26. Na BP:

$\operatorname{Sim} \square$ Não

$\square$
Estudas
Pesquisas e acedes a informação da biblioteca para estudo
Pesquisas e acedes a informação da biblioteca para lazer
- Se sim, utilizas esta informação para estudo?
$\square \operatorname{Sim}$
$\square$ Não
$\square$ Fazes trabalhos
Utilizas a Internet
Requisitas material
Outra:

27. Na BP existe formação de utilizadores?

28. Frequência de utilização dos recursos da BP:

\begin{tabular}{|l|l|l|l|l|l|}
\cline { 2 - 7 } \multicolumn{1}{l|}{} & Nunca & Raramente & Ás vezes & Frequentemente & Muito frequentemente \\
\hline Catálogo de fichas & & & & & \\
\hline Acesso livre & & & & & \\
\hline *Biblioteca Digital & & & & & \\
\hline Catálogo electrónico & & & & & \\
\hline $\begin{array}{l}\text { Bases de dados } \\
\text { electrónicas }\end{array}$ & & & & \\
Sentes dificuldade em usar os recursos da BP? \\
29.1. Se sim, a quem recorres para dar resposta a
\end{tabular}
dificuldades?

\begin{tabular}{|l|l|l} 
Bibliotecário & & Pessoal de apoio \\
\cline { 2 - 2 } Colegas & Familiares \\
\hline
\end{tabular}

Sim

Não

Outro:

30. Que tipo de recursos de informação a BP te disponibiliza?

\begin{tabular}{|l|l|l} 
& Livros \\
Vídeos & $\begin{array}{l}\text { Jornais } \\
\text { Música }\end{array}$ \\
Informação em formato electrónico & $\square$ & Revistas \\
Jogos
\end{tabular}

Outro: 
31. De uma forma geral, com que frequências acedes á Internet?
Nunca
1 vez na semana
Raramente $\square 1$ vez no mês
$\square$ Várias vezes na semana
Várias vezes no mês
Diariamente

32. Habitualmente, onde acedes à Internet?
Casa $\square$ Escola
Casa de amigos
$\square \mathrm{BP}$ Local de trabalho
BE
CyberCafé

33. Frequência de utilização dos motores de pesquisa na Internet:

\begin{tabular}{|l|l|l|l|l|l|}
\hline & Nunca & Raramente & Às vezes & Frequentemente & Muito frequentemente \\
\hline Google & & & & & \\
\hline Yahoo & & & & & \\
\hline Sapo & & & & & \\
\hline AEIOU & & & & & \\
\hline Outro: & & & & & \\
\hline
\end{tabular}

34. Frequência de utilização dos recursos da Internet:

\begin{tabular}{|l|l|l|l|l|l|}
\cline { 2 - 6 } \multicolumn{1}{c|}{} & Nunca & Raramente & Ás vezes & Frequentemente & Muito frequentemente \\
\hline YouTube & & & & & \\
\hline Wikipédia & & & & & \\
\hline Sites de bibliotecas & & & & & \\
\hline Blogues & & & & & \\
\hline Rádio/Música & & & & & \\
\hline Hi5/semelhantes & & & & & \\
\hline Messenger/semelhantes & & & & & \\
\hline${ }^{*}$ Biblioteca digital & & & & & \\
\hline Fazer Uploads & & & & & \\
\hline Fazer Downloads & & & & & \\
\hline
\end{tabular}

35. Indica três assuntos do teu interesse:
Informação e sociedade
Arte
Entretenimento
Educação / Emprego

Outro:

\section{RECUPERAÇÃO E USO DA INFORMAÇÃO}

36. Para além da BP, BE e da Internet onde pesquisas informação?

\begin{tabular}{|l|l|l|}
\hline Jornais & & TV \\
$\begin{array}{l}\text { Revistas } \\
\text { Filmes/documentários }\end{array}$ & Rádio \\
$\begin{array}{l}\text { Outro: } \\
\text { Oessoas (professores, colegas, familiares, etc.) }\end{array}$ \\
\hline
\end{tabular}

37. Para fazeres um trabalho com que frequência utilizas os instrumentos apresentados:

\begin{tabular}{|l|l|l|l|l|l|}
\cline { 4 - 6 } \multicolumn{1}{c|}{} & Nunca & Raramente & Às vezes & Frequentemente & $\begin{array}{l}\text { Muito } \\
\text { frequentemente }\end{array}$ \\
\hline Apontamentos das aulas & & & & & \\
\hline Manuais para a disciplina & & & & & \\
\hline $\begin{array}{l}\text { Bibliografia dada pelo } \\
\text { professor }\end{array}$ & & & & & \\
\hline Material existente na BE & & & & & \\
\hline Material existente na BP & & & & & \\
\hline Motores de pesquisa na & & & & & \\
\hline
\end{tabular}




\begin{tabular}{|l|l|l|l|l|l|}
\hline Internet & & & & & \\
\hline Páginas Web & & & & & \\
\hline
\end{tabular}

38. Na pesquisa para um trabalho, dos resultados que obténs, o que consultas (selecciona apenas uma opção)?

\begin{tabular}{|l|l} 
Todos os que são apresentados \\
$\square$
\end{tabular} Todos os resultados da primeira página $\quad \begin{aligned} & \text { Mais do que uma página de resultados, mas não todas } \\
& \text { Alguns resultados da primeira página }\end{aligned}$

39. Dos resultados de pesquisa que consultaste, como seleccionas os que vais utilizar?
$\square$ Pela origem/fonte de informação
Pelo resumo apresentado
Pela ordem de apresentação
Pelo conteúdo

40. Imprimes/fotocopias a informação seleccionada?

41. De que forma tratas a informação seleccionada?

$\square \operatorname{Sim} \square$ Não
$\square$ Ler
Comparar com outras leituras
Copiar/passar textualmente
Tirar apontamentos
Avaliar a autoria

42. A quem solicitas ajuda para fazeres um trabalho?
A ninguém
Colegas
Grupo de trabalho
Familiares
$\square$ Professores

43. Inicias o teu trabalho directamente no processador de texto? (ex.: Word)

44. Habitualmente, inicias a realização do teu trabalho:

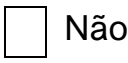

$\square$ No dia em que te é atribuído pelo professor

Na semana anterior à data de entrega

Na véspera da data de entrega

45. Ordena os seguintes elementos de forma a apresentares a estrutura usual que dás a um trabalho (1primeiro a 6 - último)

$\square$ Apêndice

46. Por hábito

alguém antes

47. Em que

$\square$ Papel $\square$ Introdução

Não

48. Habitualmente, é-te pedido que apresentes na aula o trabalho realizado? 48.1. Se sim, em que formato?
$\square$ PowerPoint
Oralmente
Flash

49. Das fases de realização de um trabalho, a seguir apresentadas, selecciona a tarefa à qual dedicas mais tempo (apenas uma):

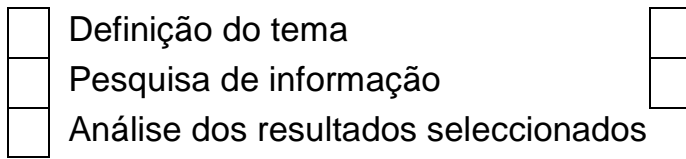

Redaç̧ão do texto

Selecção dos resultados de pesquisa

50. Das fases de realização de um trabalho, a seguir apresentadas, selecciona a fase que consideras mais importante (apenas uma):
$\square$ Pesc
Definição do tema
Pesquisa de informação
Análise dos resultados seleccionados
Redacção do texto
Selecção dos resultados de pesquisa

51. Conheces alguma norma para referenciação bibliográfica? (por exemplo: ISO 690; Norma Portuguesa 405; a da Associação de Psicologia Americana - APA; Moderna Standard Association - MLA; normas do estabelecimento de ensino/curso etc.)

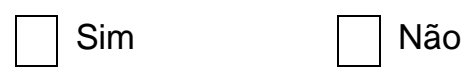

52. Referências Bibliográficas: dos exemplos a seguir apresentados, escolhe a hipótese correcta.

Teun A. Van Dijk - Texto e Contexto: semântica e pragmático do discurso. Introd. de António Garcia 
Berrio; trad. de Juan Domingo Moyano. $2^{\mathrm{a}}$ ed. Madrid: Cátedra, 1984. 357 p. (Crítica y Estudios Literários). Tradução de: Text and context. ISBN 84-376-0219-X

$\square$ DIJK, Teun A. van - Texto e Contexto: semântica e pragmático do discurso. Crítica y Estudios Literários. Madrid: Cátedra, 1984. 357 p. Tradução de: Textand context. ISBN 84-376-0219-X

$\square$ DIJK, Teun A. van - Texto e Contexto: semântica e pragmático do discurso. Introd. de António Garcia Berrio; trad. de Juan Domingo Moyano. 2ª ed. Madrid: Cátedra, 1984. 357 p. (Crítica y Estudios Literários). Tradução de: Text and context. ISBN 84-376-0219-X

Todas as hipóteses estão correctas

Nenhuma das hipóteses está correcta

53. Citações: dos exemplos a seguir apresentados, escolhe a hipótese correcta.

$\square$.... segundo Goldstein (1984, p. 47) como moduladores da fluidez lipídica, em particular,... ... " como moduladores da fluidez lipídica, em particular" (GOLDSTEIN, 1984, p.47) ...

Todas as hipóteses estão correctas

54. Se te auto avaliasses como considerarias:

\begin{tabular}{|l|l|l|l|l|}
\cline { 2 - 5 } \multicolumn{1}{c|}{} & Insuficiente & $\begin{array}{l}\text { Suficiente, mas } \\
\text { com dificuldades }\end{array}$ & Suficiente & $\begin{array}{l}\text { Mais do que } \\
\text { suficiente }\end{array}$ \\
\hline $\begin{array}{l}\text { Os conhecimentos que possuis para } \\
\text { avaliar e seleccionar os resultados } \\
\text { obtidos }\end{array}$ & & & & \\
\hline $\begin{array}{l}\text { Os conhecimentos que possuis para } \\
\text { sistematizar e produzir o trabalho } \\
\text { pretendido }\end{array}$ & & & & \\
\hline
\end{tabular}

FIM DO INQUÉRITO. OBRIGADO. 


\section{APÊNDICE 2 - MODELO ELIT.PT}

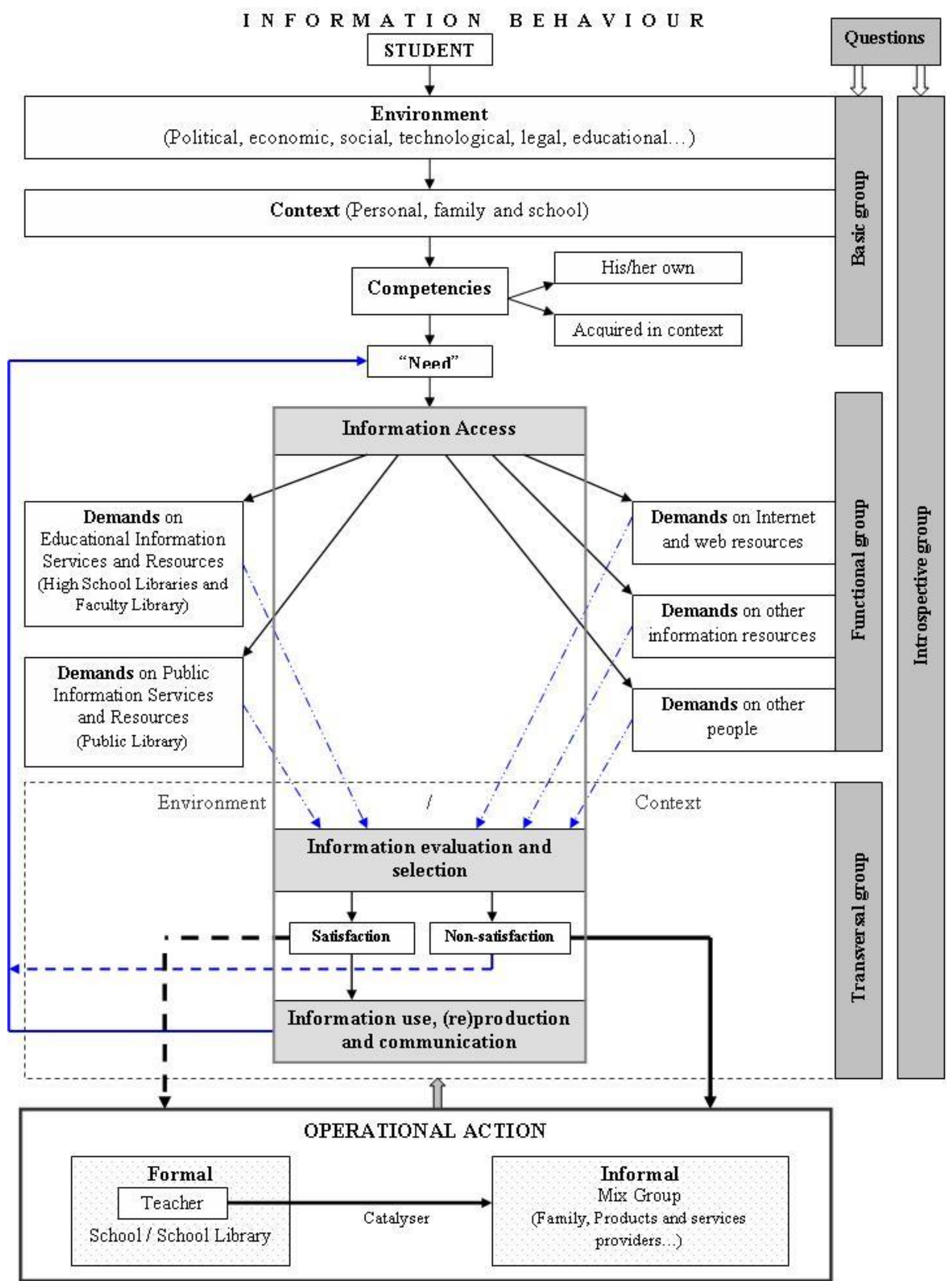

